\title{
AC 2009-638: A MODULAR APPROACH IN THE DEVELOPMENT OF CURRICULA FOR AEROSPACE SCHOOLS PROVIDES FLEXIBILITY AND UNIFORMITY
}

John Anderson, Oregon Institute of Technology

Sergey Dubikovsky, Purdue University

Ronald Way, El Camino College

Bradley Harriger, Purdue University

Buford Pringle, Butler Community College

Scott Schaffer, Purdue University 


\title{
Modular Approach in Development of Curriculum for Aerospace Schools Provides Flexibility and Uniformity
}

\begin{abstract}
The aerospace industry is going through a period of radical change. As products become increasingly complex, engineering technicians must be more specialized, obtaining skills that, until recently, were used only by "pure" engineers. At the same time, the demand for skilled maintenance personnel is growing. The Bureau of Labor Statistics predicts the need for aerospace engineering and operations technicians will increase ten percent between 2006 and 2016, compared with a 7 percent overall employment growth in the need for engineering technicians. Furthermore, notwithstanding today's more sophisticated technology, employers are looking for a well-prepared workforce that requires little or no on-site training. Another problem in the aerospace industry is an aging workforce (average age mid 40s or older) that will begin retiring in large numbers in the near future. This reality creates an urgent need for new approaches in two-year aerospace programs. El Camino College, Butler Community College, Oregon Institute of Technology and Purdue University are all developing new model curricula for technicians and engineers in the aerospace industry. These curricula will cover the gamut of the needs for manufacturing technologists in the aerospace industry and will also provide a common fluency in aerospace manufacturing procedures, processes, and terminology. One proposed modular approach allows an instructor to select needed section(s) for any course from available national "pool" of information, with each module including PowerPoint data, Instructor notes, and a student study guide. This approach will make developing new courses or redesigning existing courses easier and more uniform throughout aerospace schools. It is clear that a tradeoff exits: too much modularization suggests lack of cohesion; the reverse suggests lack of flexibility. The modules' development is still in the formative stages with a focus on validating them within a variety of academic contexts. The next phase of activity may involve movement toward certification which would require more curricular cohesion and moving beyond pre-post criterion-referenced testing to standardized tests.
\end{abstract}

\section{Introduction}

This work is being funded by a National Science Foundation grant entitled "Advanced Aerospace Manufacturing Education Project” (NSF Award \#0603221).The aerospace manufacturing industry is undergoing radical change. These changes are being driven by an aging workforce (average age mid 40s or older) that will begin retiring in large numbers in the near future and by pressure from its customers to dramatically increase productivity in an increasingly complex product. It is projected that by 2009, 27 percent of the US aerospace workforce will be at retirement age ${ }^{1}$. The manufacturing team, including production support, that assembles aerospace products, includes mechanics, technicians, production managers, and manufacturing engineers. Training and education should be consistent to establish fluency in advanced manufacturing technologies. The primary source of training and education is the community college system. 
The grant enables El Camino College, Butler Community College, Oregon Institute of Technology and Purdue University to develop model curricula for manufacturing technicians and engineers working in the aerospace industry. These curricula will cover the gamut of the needs for manufacturing technologists in the aerospace industry and will also provide a common fluency in aerospace manufacturing procedures, processes, and terminology. The need for a pool of skilled technology workers in this industry is highlighted by the aging of the existing workforce and demands for increased manufacturing efficiency with an increasingly complex product. The civilian and military aerospace industries share some common problems, thereby making this a national problem. This proposal brings together United States aerospace, four leading academic institutions involved in training and education of manufacturing technologists, two leading professional societies serving this segment of industry, and numerous leading national and international suppliers of equipment and services to the aerospace industry.

\section{Background}

Estimates of current employment in the aerospace sector, including its supply chain, range as high as 790,000 production workers $^{2}$. It is also important to note that the production jobs in aerospace are compensated well. Aerospace production workers earn approximately 1.3 times the average hourly earnings for all manufacturing workers and 2.2 times that of hourly earnings for retail workers ${ }^{1}$. Total payroll for the US aerospace industry is in excess of $\$ 98$ billion dollars. The aerospace industry is nationwide, with California, Texas, and Washington having the largest employment and significant clusters in Alabama, Arizona, Georgia, and Kansas ${ }^{3}$. It is important that a pool of workers exists who have the correct set of skills for this industry. The tools and techniques used in aerospace manufacturing are changing rapidly. It is important that the workforce not only have the technical skills to operate and maintain the equipment, but also an understanding of teamwork and modern manufacturing concepts, such as lean manufacturing.

The traditional hand/master mechanic methods of manufacturing can no longer attain the demanding tolerances that are inherent in modern aircraft. The complex systems that comprise a modern air vehicle require sophisticated technologies and components to meet the specified requirements for fabrication and assembly. The technologies that are emerging to meet the requirements for airframe assembly and its systems have been developed and are being introduced to the manufacturing centers that produce and will produce the modern air vehicles. The introduction of the sophisticated technologies for manufacture of modern air vehicles requires a new type of aerospace manufacturing technologist that is educated and trained to understand and operate modern day systems entering production ${ }^{4}$.

The placement of nearly or approximately aligned skill sets to do on-the-job training presents risks too great for the training to be applied on the airframe, where a single error can cause a significant defect resulting in tens, if not hundreds of thousands of dollars in defects and disruption to the manufacturing process. Therefore, the need for a new type of manufacturing engineer/technologist who possesses the necessary skills and knowledge is an absolute requirement for the future of aerospace manufacturing to provide increasing demands required for the current and future generation aircraft. 
Additionally, national defense implications of the aerospace industry place additional importance on having a well trained and educated pool of manufacturing workers. The US cannot afford to lose the means to produce weapons to defend itself, and cannot depend on production of weapons systems in other countries for political and military reasons. In addition to the national defense considerations, the aerospace industry contributed a trade surplus of approximately $\$ 31$ billion to the U.S. economy in $2004^{5}$.

The aerospace industry is unique in many areas that differentiate it from other manufacturing industry models, methods, processes and technologies. The types of varied materials and the expense of fabrication of the components, assembly tolerances, coatings and systems testing have generated the need for highly sophisticated types of manufacturing technology systems that are only produced by a limited number of manufacturers worldwide. Therefore the production of these highly sophisticated systems and their specific application to airframes and aerospace systems requires a unique skill set that is not inherent within the current training and/or educational programs, courses or classes. The value of a technologist who is trained in the specifics of the unique manufacturing methods resident in aerospace products is distinct and identifiable and therefore capable of being taught as a specialized and defined curriculum where the outcome would benefit all areas of aerospace including space systems, and unmanned and manned vehicles. Such education and training would produce an individual who would add great value to the industrial base of both the commercial and military sectors by providing industry ready professional technologists for immediate integration into the production stream. The Bureau of Labor Statistics predicts the need for aerospace engineering and operations technicians will increase ten percent between 2006 and 2016, compared with a 7 percent overall employment growth in the need for engineering technicians. Furthermore, notwithstanding today's more sophisticated technology, employers are looking for a well-prepared workforce that requires little or no on-site training ${ }^{4}$.

\section{Funded Project}

Curriculum development approaches considered for this project ranged from the creation of a full degree program to the creation of a series of elective courses to the development of targeted materials on select topics. All were capable of offering the appropriate content capable of generating student interest and addressing identified competency gaps ${ }^{6}$; however, the project team decided to go with the course modules approach in order to provide more flexibility for programs and faculty wishing to adopt materials created by the project.

The manufacturing related instructional modules developed, parallel common topics found in traditional engineering technology courses, but with an added aerospace slant. This approach provides the educator a means by which they can enhance and/or embellish existing course materials with materials generated by the project. This additionally gives the educator or the institution the ability to pick and choose what best fits the class without the problem of trying to squeeze a new elective course into a program.

The aerospace manufacturing related modules are divided into areas such as:

- Composites

- Materials 
- Assembly

- Fasteners

Although there is some overlap, for example in Composites and Materials, the focus of the modules in each area is different. Each area contains multiple modules.

The modules are sized to provide approximately 2 lecture hours of material. An example of this is the Introduction to Composites module. This is designed to cover the basics of composites, as well as offer some information on manufacturing techniques. This module consists of 38 Power Point slides and an instructor manual with student activities. For example, the following slide illustrates a fiber reinforced composite.



Each slide is accompanied by a description and notes in the instructor notes. The section for the slide above is;

8. This slide illustrates 2 layers of fibers in a matrix. Note that all the fibers are oriented in the same direction. The fibers are much stronger than the matrix material, so the response to a force applied parallel to the fiber length is much different than the response to a force applied perpendicular to the fiber length.

This approach minimizes the preparation time for the instructor.

Another example is; 


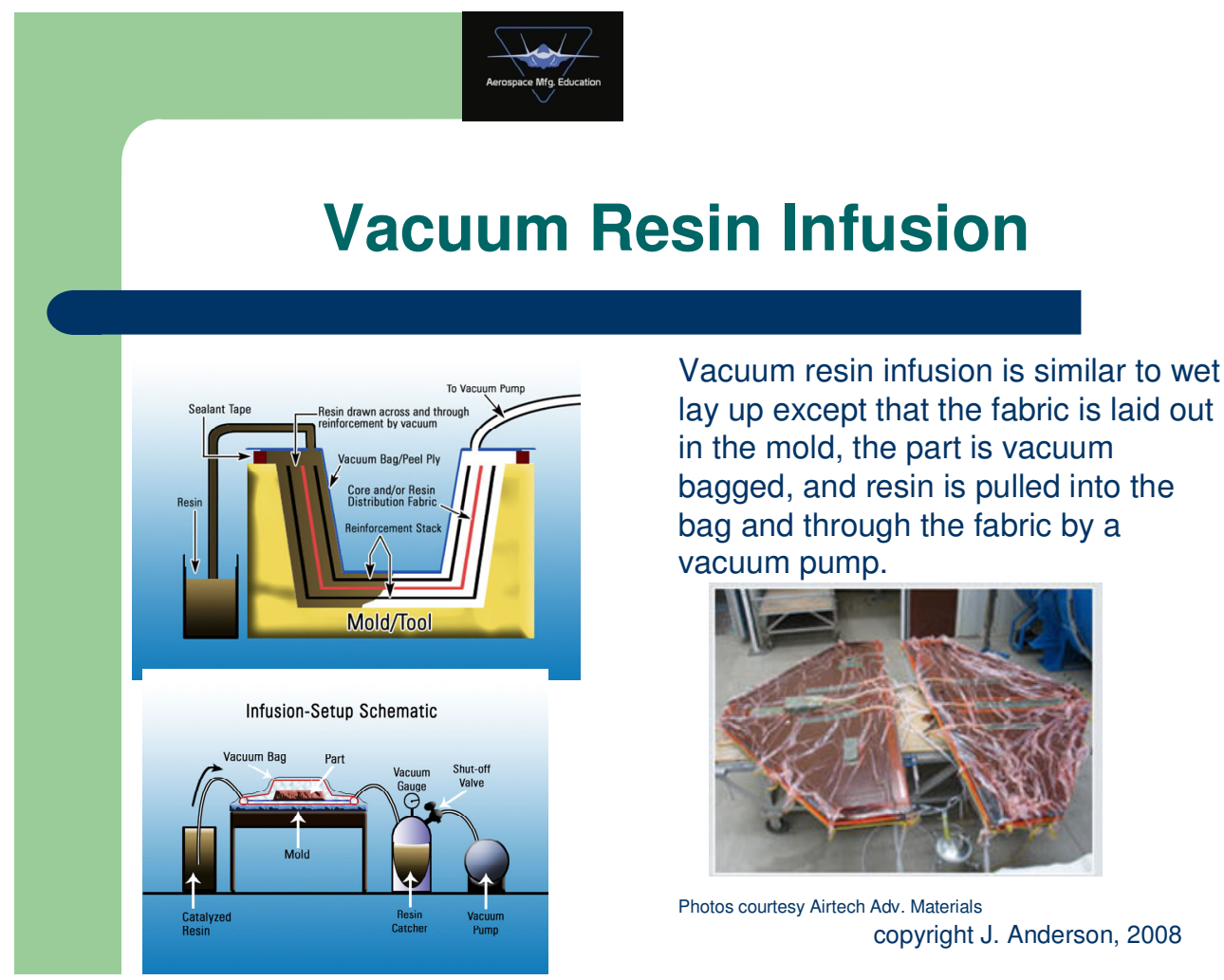

For this slide the instructor notes are;

30. Vacuum resin infusion is a technique that seeks to make the wet layup process more efficient. The illustration on the slide shows how the process works. A part is laid up and bagged as in the wet layup process, but no resin is added. A resin supply is introduced on one side of the bag and a a vacuum pump on the other. As the bag is sucked down on the fabric resin is pulled through and over the fibers. The advantage of this process is tighter control over the ratio of matrix to fiber. The higher the fiber to matrix ratio in the part, the higher the strength to weight ratio.

A good description of the infusion process is in the paper "Vacuum Infusion - The Equipment and Process of Resin Infusion" from Fibreglast at http://www.fibreglast.com/documents/361.pdf . Another supplier of resin infusion systems for aerospace applications is AirTech at http://www.resininfusion.com/infusiontech.html .

Videos of the vacuum resin infusion process may be found at http://www.youtube.com/watch?v=noRRQ_1BMtQ\&feature=related . A vacuum infusion of aircraft fuselage is at http://www.youtube.com/watch?v=-efttvlRbO8\&feature=related A vacuum infusion of aircraft bulkhead is at http://www.youtube.com/watch?v=-efttvlRbO8\&feature=related 
To increase the flexibility of these materials they are offered in the public domain in "editable" format, such as Word and Power Point.

Student activities are also suggested in the instructor notes. An example is;

Student Activities:

- Identify 3 products you have used or are aware of that have a composite materials in their construction. Explain what advantage composites offer in the performance of these products.

- Ten Cate Aerospace Composites is a manufacturer of high performance composite systems. Using the internet, answer the following questions;

○ For the BT250E-1 Resin System, what are some typical applications?

- What is the shelf life and how would this impact manufacturing operations?

- One of the ways in which composites fail is by de-lamination of the plies. Explain why this happens. How would you modify a multi layer composite to reduce the risk of this type of failure?

\section{Formative evaluation}

Two types of evaluation will be used to validate the curriculum. Formative evaluation will consist of two major phases: design review and learner validation. Design review will determine the degree of alignment between program objectives, curriculum content, and types of learner assessment. Following revision of content modules based on evaluative feedback, learner tryouts will be conducted to assure that instructional materials are clear and understandable to the target audience. The instructional materials will be reviewed in one-on-one sessions with learners from the target population (current students, current employees), in order to ensure face validity of the materials (e.g. materials comprehensible to target population). Following this evaluation, instruction will be piloted with appropriate learners to determine how well they learn from the instruction and to identify potential problems that could arise. Small group evaluation will be utilized for this segment. Groups will be intact classes where the materials are being piloted. A pre- post - post test design to assess learning and transfer will be employed using a criterion referenced assessment approach which will help to identify specific parts of the curriculum that work well and parts in need of modification. Finally, summative evaluation processes will be conducted to determine the degree to which learners achieve learning goals, how they feel about instruction, costs of instruction, unexpected outcomes, and the overall success of the dissemination of the program to faculty and industry partners.

\section{Results}

One of the modules was presented to students of a basic composite class in the last two weeks of the class. The class was an 8 week class. The module was presented as a lengthy power point. The actual presentation amounted to a course summation. The group used the DVD series from SME for several of the presentations and the rest of the presentation material came from the textbook, Fundamentals of Composites Manufacturing, A. Brent Strong. The actual presentation took around 1.5 hours. A pre-test was developed for the module and was administered as a quiz before the module was presented. Then after the module was presented the pre-test was scrambled and administered to students one class period later. The results were as follows: 
Pre-test average score: $\quad 67.5$

Pretest range: $\quad 55-80$

Median score $\quad 67.5$

The post test scores showed a dramatic change:

Post test average $\quad 81.67$

Post test range $75-90$

Median score 82.5

\section{Conclusions}

Results of this project will be offered for presentation at professional society conferences such as those of the American Society of Engineering Educators, the National Association for Industrial Technology, the Society of Manufacturing Engineers, and the American Society of Mechanical Engineers. Results of this project will also be offered for presentation through educational associations such as the California Association of Occupational Education and through professional journals aimed at engineering and technical educators.

A series of workshops will be offered to introduce faculty at other schools to the curricular tools developed through this project. Instructors should realize that too much modularization suggests lack of cohesion; the opposite would lead to lack of flexibility. The development of the project is still in the formative stages with a focus on validating the modules within a variety of academic contexts. The next phase of activity may involve movement toward certification which would require more curricular cohesion and moving beyond pre-post criterion-referenced testing to standardized tests. A stipend and travel allowance will be offered to help participants interested in adopting these materials to defray the cost of attending the workshops. In addition, it is planned to offer these workshops in conjunction with conferences and expositions offered by professional societies. A total of 27 stipends will be offered for the workshops. Inclusion of at least 27 faculty at other schools should provide a significant seed effort throughout the country.

\section{References}

[1] McMillin, M., Layoffs Age Aerospace Industry. The Wichita Eagle( June 29, 2003).

[2] Faux, J., The Aerospace Sector as a National Asset. Testimony before the Commission on the Future of the United States Aerospace Industry, May 14, 2002.

[3] Tracy, J., Drivers and Challenges for US Aerospace Manufacturing, The Boeing Company, New Directions in Manufacturing: Report of a Workshop, Committee on New Directions in Manufacturing, National Research Council, 2004. 
[4] Bureau of Labor Statistics, U.S. Department of Labor. Occupational Outlook Handbook, 2008-09 Edition, Engineering Technicians. Retrieved December 21, 2008 from http://www.bls.gov/oco/ocos112.htm.

[5] Aerospace Industries Association press release. Retrieved September 6, 2005 from http://www.aia-aerospace.org/aianews/press/press.cfm

[6] Anderson, J., Advanced Aerospace Manufacturing Education Project, Proceedings of the Annual Meeting of the American Society for Engineering Education, June 2007. 